\section{Shuttlebox avoidance programs for the 6502}

\section{DAVID S. MALCOLM \\ Fairleigh Dickinson University, Rutherford, New Jersey}

Two programs were written in assembly language for the 6502 microprocessor to control a wide variety of learning procedures for a shuttlebox. Both programs can control two shuttleboxes simultaneously.

The first program includes routines for the traditional discrete-trial avoidance procedures, including operant level (CS only), avoidance, punishment, and Pavlovian conditioning (US presentation independent of the response). Session parameters (number of trials, durations of the CS, US, and ITI) may be set over a wide range of values, and response-contingent CS termination is an option. Session-identification data, the latency of the first response on each trial, and the total number of intertrial responses are both printed and stored in memory. Latencies, rather than just the occurrence of a response, are measured. Bolles (1979) argued that the failure of the response latencies to change over time is evidence that the animal is showing a species-specific defense reaction rather than avoidance learning.

The second program controls the linear presentation procedure described by Zerbolio (1981). This method was developed with the thought that the traditional shuttlebox avoidance procedures do not provide unambiguous evidence for the acquisition of a discriminated avoidance response in goldfish. In the typical avoidance learning experiment, an increase in response rate is taken as evidence for learning. Goldfish present a problem in that they are known to increase their rate of responding not only in the situation in which there is response-contingent shock omission, but also under a large variety of procedures, including no US presentation (Steiner, 1971) and Pavlovian procedures (Woodard \& Bitterman, 1971). Zerbolio's procedure provides a parallel to the response requirements of a Y maze. In the shuttlebox, each trial begins with a trial-start stimulus. If the fish responds, by shuttling to the other end of the tank, either an S+ or an S - stimulus is presented on a randomized basis. If the fish makes additional responses on this trial, the $\mathrm{S}+$ and $\mathrm{S}-$ stimuli alternate. At the end of the trial, the fish receives the US if the trial-start or S - stimuli are in effect. To avoid the

\footnotetext{
The author's mailing address is: Department of Psychology, Farleigh
} Dickinson University, Rutherford, NJ 07070.
US, the fish must make an initial shuttle response to change the trial-start stimulus into the $S+/ S-$ stimulus, and an additional response only if the $S-$ stimulus is presented. With this procedure, evidence for a learned discriminated avoidance is obtained if the fish avoids on significantly more than one-half of the trials. No other response pattern, including an increased rate of responding on all trials, would produce more than a $50 \%$ avoidance rate. The data recorded by this program include the number of responses per trial, US delivery, ITI reponses, and the initial stimulus presentation. The same session parameters may be set as in the avoidance program; in addition, the sequence of initial $S+/ S-$ stimuli can be set.

Session- and fish-identification data and the response data are stored in memory in both programs to allow for additional analysis.

Program Requirements. These programs were written for the Rockwell AIM-65 microcomputer. They can be adapted to any 6502-based microcomputer with at least $2 \mathrm{~K}$ of RAM and with a 6522 VIA available to the user, such as the KIM, SYM, and many Commodore microcomputers. Other 6502-based microcomputers, such as the Apple, would require the addition of a 6522 parallel I/O card (e.g., that available from John Bell Engineering, P.O. Box 338, Redwood City, California 94064, Model 79-295).

As written, the programs use some subroutines from the AIM- 65 monitor, primarily routines that serve the keyboard and printer. Equivalent routines are available in the monitors of other computers.

Availability. Annotated source code listings may be obtained free of charge from the author. AIM-65 users may obtain both source and object code on tape by providing a blank tape and specifying the tape-gap size required.

\section{REFERENCES}

Bolles, R. C. (1979). Learning theory (2nd ed.). New York: Holt, Rinehart \& Winston.

STEINER, G. (1971). Stimulus control of avoidance learning in fish. Journal of Comparative and Physiological Psychology, 74, 52-58.

WoOdard, W. T., \& BitTerman, M. E. (1973). Pavlovian analysis of avoidance conditioning in the goldfish (Carassius auratus). Journal of Comparative and Physiological Psychology, 82, 123-129.

Zerbolio, D. J. (1981). Discriminated avoidance learning and reversal by goldfish in a shuttlebox using a linear presentation procedure. Animal Learning \& Behavior, 9, 346-356.

(Revision accepted for publication January 31, 1985.) 